\title{
Modeling, simulation and testing of a silicon soil moisture sensor based on the dual-probe heat-pulse method
}

\author{
A. Valente ${ }^{\mathrm{a}, *}$, R. Morais ${ }^{\mathrm{a}}$, C. Couto ${ }^{\mathrm{b}}$, J.H. Correia ${ }^{\mathrm{b}}$ \\ ${ }^{a}$ UTAD University, Engenharias II, Quinta de Prados, 5000-911 Vila Real, Portugal \\ ${ }^{\mathrm{b}}$ UM, University of Minho, Campus de Azurém, 4800-058 Guimarães, Portugal \\ Received 6 October 2003; received in revised form 15 April 2004; accepted 16 April 2004 \\ Available online 2 July 2004
}

\begin{abstract}
A silicon soil moisture sensor, based in the dual-probe heat-pulse (DPHP) method, was modeled, simulated and tested for achieving, with low-cost, accurate and reliable measurements. This method is based on the application of a heat pulse during a fixed interval of time. The maximum rise in temperature $\left(\Delta T_{\mathrm{M}}\right)$ is monitored by the measurement probe, placed at a certain distance of the heater source. $\mathrm{A}$ low-cost high-performance and small temperature sensor (a dynamic $V_{\text {PTAT }}$ generator) was designed and fabricated to be placed into the probe which have $0.912 \mathrm{~mm}$ inner diameter and $20 \mathrm{~mm}$ long. If one considers the range of water contents, ratio of water mass to dry soil mass, in a typical agricultural soil $\left(0.05-0.35 \mathrm{~m}^{3} \mathrm{~m}^{-3}\right)$, the average sensitivity of the dual probe is about $1.95{ }^{\circ} \mathrm{C}$ per unit change $\left(\mathrm{m}^{3} \mathrm{~m}^{-3}\right)$ in water content for $q=400 \mathrm{~J} \mathrm{~m}^{-1}$.
\end{abstract}

(C) 2004 Elsevier B.V. All rights reserved.

Keywords: Soil moisture sensor; DPHP method; CMOS temperature sensor; PTAT; Dynamic element matching

\section{Introduction}

Efficient short and long-term management of irrigation systems requires the use of reliable and accurate soil moisture sensors. Today, a large number of sensors, based on nuclear, electromagnetic, tensiometric, capacitance, among others, techniques are available for measuring soil moisture. Generally, these methods have several limitations that restrict their integration in the management of irrigation systems. The main disadvantages are: soil dependency, inaccuracy and high-cost sensors.

Time domain reflectometer (TDR) sensors [1,2], which are based on the influence of soil water content over the propagation of electromagnetic waves, are independent of soil texture, temperature and salt content, but its high cost restricts the applicability to these systems.

The dual-probe heat capacity sensor has been developed to provide small scale, frequent measurements of soil thermal properties: volumetric heat capacity $\left(\rho c_{\mathrm{p}}\right)$, thermal conductivity, and thermal diffusivity $[3,4]$. The heat capacity of soil influences both the storage and transfer of heat,

\footnotetext{
* Corresponding author. Tel.: +351 259350343; fax: +351 259350480. E-mail addresses: avalente@utad.pt (A. Valente), rmorais@utad.pt (R. Morais), ccouto@dei.uminho.pt (C. Couto), jhc@dei.uminho.pt (J.H. Correia).
}

so it is a necessary parameter in models of soil temperature and heat flow. In a non-swelling soil, changes in $\rho c_{\mathrm{p}}$ are due primarily to changes in soil water content; hence, an application of the dual-probe will allow determination of volumetric soil water content $\left(\theta_{\mathrm{v}}\right)[5,6]$.

Bristow et al. [4] applied the heat-pulse technique to determine $\theta_{\mathrm{v}}$ using dual-probe sensors with two needle probes probes that were $28 \mathrm{~mm}$ long, constructed from No. 20 hypodermic tubing, and mounted $6 \mathrm{~mm}$ apart. Valente et al. [7] constructed a combination dual-probe-capacitance apparatus but with No. 18 hypodermic tubing. Power consumption, for stand-alone battery powered sensors, is the main drawback of this method. Since thermocouples are used to measure the maximum temperature rise, $\Delta T_{\mathrm{M}}$, analog-to-digital converters with adequate resolution (e.g. $0.33 \mu \mathrm{V})$ are required to detect small changes in $\theta_{\mathrm{v}}$ [5]. To obtain $\Delta T_{\mathrm{M}}$ the ambient temperature is subtracted to the temperature in temperature probe. Since, for both cases the CMOS temperature sensor is used, good accuracy is needed in temperature measurements.

A high-resolution temperature sensor enables measurements of smaller temperature differences, which in turns allows for a reduction of the heating power. Therefore, the development of a low-cost miniaturized temperature sensor with high accuracy and $0.01{ }^{\circ} \mathrm{C}$ resolution that fits into a hypodermic needle will be a breakthrough. This 
solution allows the use of an interface with electronics, network solution, and external communications that could be implemented in the sensing system near the temperature sensor. Although the reports of a bulk-micro-machined sensor [8] documented the performance of the dual-probe heat-capacity micro-sensor in measuring $\theta_{\mathrm{v}}$, their experiments were conducted in laboratory setting. Robustness of the micro-sensor under field conditions have to be improved.

Hence, the development of a low-cost dual-probe heat-pulse (DPHP) sensor of about $30 \mathrm{~mm}$ long $\times 10 \mathrm{~mm}$ wide $\times 3 \mathrm{~mm}$ in height; with a probe pitch of $3 \mathrm{~mm}$ will provide small-scale spatial measurements of soil moisture, which can be made near the soil surface where large root densities are found. The use of steel hypodermic needles mounted in an acrylic block will provide robustness of the soil moisture sensor and minimize errors due to deviations in probe spacing.

\section{Theory}

The volumetric heat capacity of soil, $\rho c_{\mathrm{p}}\left(\mathrm{J} \mathrm{m}^{-3}{ }^{\circ} \mathrm{C}^{-1}\right)$, is evaluated by adding the volumetric heat capacities of soil constituents [9]:

$\rho c_{\mathrm{p}}=1.92 X_{\mathrm{m}}+2.51 X_{\mathrm{o}}+4.18 \theta_{\mathrm{v}}$

where $X_{\mathrm{m}}, X_{\mathrm{o}}$, and $\theta_{\mathrm{v}}$ are the mineral, organic, and water fractions of the soil, respectively. The leading coefficients represent the volumetric heat capacity $\left(\mathrm{MJ} \mathrm{m}^{-3}{ }^{\circ} \mathrm{C}^{-1}\right)$ of each soil constituent.

The temperature distribution due to an instantaneous release of heat from an infinite line source ([10], p. 258) is:

$T(r, t)=\frac{Q}{4 \pi \kappa t} \exp \left(\frac{-r^{2}}{4 \kappa t}\right)$

in which $T$ is the temperature rise $\left({ }^{\circ} \mathrm{C}\right), t$ is time (s), $r$ the radial distance from the heater $(\mathrm{m})$, and $\kappa$ is the thermal diffusivity $\left(\mathrm{m}^{2} \mathrm{~s}^{-1}\right)$. The source strength per unit length $\left(\mathrm{m}^{2}{ }^{\circ} \mathrm{C}\right)$, $Q$, is defined as:

$Q=\frac{q}{\rho c_{\mathrm{p}}}$

where $q$ is the heat input $\left(\mathrm{J} \mathrm{m}^{-1}\right)$ or quantity of heat liberated per unit length of heater.

The maximum rise in temperature $\left(\Delta T_{\mathrm{M}}\right)$ at some distance from the heater is measured. As mentioned by Campbell et al. [3] the relationship between the $\rho c_{\mathrm{p}}$ and $\Delta T_{\mathrm{M}}$ is:

$\rho c_{\mathrm{p}}=\frac{q}{\mathrm{e} \pi r^{2} \Delta T_{\mathrm{M}}}$

where e is the base of natural logarithms. Substituting Eq. (1) into Eq. (4) and rearranging yields an expression that shows the relationship between $\theta_{\mathrm{v}}$ and $\Delta T_{\mathrm{M}}$ :

$\Delta T_{\mathrm{M}}=\frac{q}{\mathrm{e} \pi r^{2}\left(1.92 X_{\mathrm{m}}+2.50 X_{\mathrm{o}}+4.18 \theta_{\mathrm{v}}\right)}$ or,

$\theta_{\mathrm{v}}=\frac{1}{4.18}\left(\left(q / \mathrm{e} \pi r^{2} \Delta T_{\mathrm{M}}\right)-\left(1.92 X_{\mathrm{m}}+2.50 X_{\mathrm{o}}\right)\right)$

Although $\Delta T_{\mathrm{M}}$ varies with $\rho c_{\mathrm{p}}$ and $\theta_{\mathrm{v}}, q$ can be selected to produce an adequate temperature signal for the expected range of $\theta_{\mathrm{v}}$ for a typical agricultural soil $(0.05-$ $0.35 \mathrm{~m}^{3} \mathrm{~m}^{-3}$ ).

From a oven-dry to saturated soil, $\Delta T_{\mathrm{M}}$ varies by only about $1.2{ }^{\circ} \mathrm{C}$; therefore, accurate measurements of $\Delta T_{\mathrm{M}}$ are required to correctly estimate $\theta_{\mathrm{v}}$. Taking the partial derivative of $\Delta T_{\mathrm{M}}$ with respect to $\theta_{\mathrm{v}}$ yields the sensitivity of temperature rise to the change in soil water content:

$\frac{\partial \Delta T_{\mathrm{M}}}{\partial \theta_{\mathrm{v}}}=\frac{-4.18 q}{\mathrm{e} \pi r^{2}\left(1.92 X_{\mathrm{m}}+2.50 X_{\mathrm{o}}+4.18 \theta_{\mathrm{v}}\right)}$

If one considers the range of water contents in a typical agricultural soil, the average sensitivity of the dual-probe is about $2.5^{\circ} \mathrm{C}$ per unit change $\left(\mathrm{m}^{3} \mathrm{~m}^{-3}\right)$ in water content; that is, a $1 \%$ change in $\theta_{\mathrm{v}}$ cause a $0.025^{\circ} \mathrm{C}$ change in $\Delta T_{\mathrm{M}}$.

\section{Projected system}

The system consists of two needle probes mounted in parallel to provide a heater and a sensor probe. The needles will be made from stainless steel tubing, $1.27 \mathrm{~mm}$ outer diameter, which will protrude $20 \mathrm{~mm}$ beyond the edge of the acrylic mounting [7].

The heater will be made from Stablohm 800A wire and placed in the middle of 'heater' needle. A high-accuracy CMOS temperature sensor with amplifier will be placed in the center of the 'probe' needle. The needles will be filled with high-thermal-conductivity epoxy glue to provide water-resistant, electrically insulated probes. The complete projected system is illustrated schematically in Fig. 1. $\Delta T_{\mathrm{M}}$ measurements will be obtained from the difference between the CMOS temperature sensor placed in the acrylic mounting (reference) and one identical temperature sensor placed in the middle of the temperature probe.

\section{Heat-pulse simulations}

Experimentally, it is not possible to heat the line source instantaneously, so a short-duration heat pulse is used. The

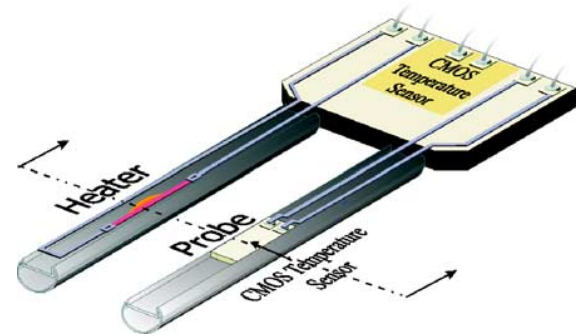

Fig. 1. The complete soil moisture sensor projected system. 


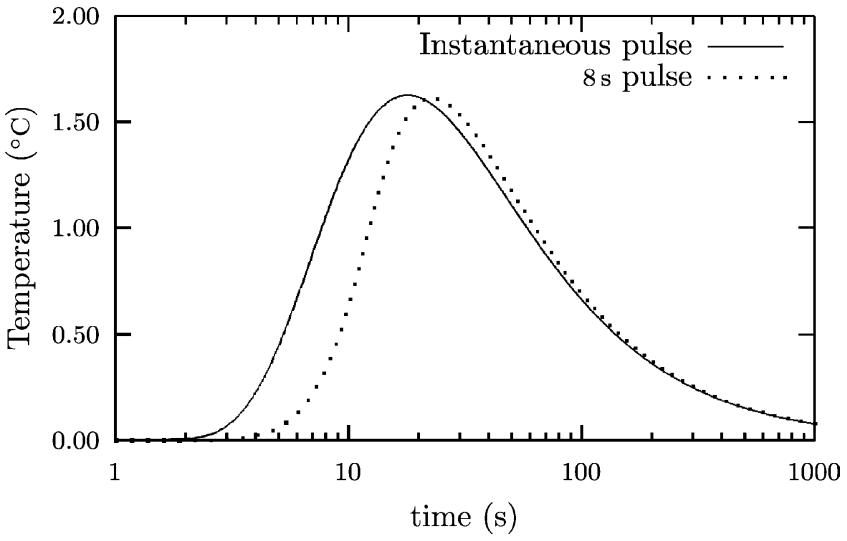

Fig. 2. Temperature results based on analytical models for instantaneous and pulsed line source.

solution for radial conduction of a short-duration, $t_{0}(\mathrm{~s})$, heat pulse away from a cylinder of radius $a(\mathrm{~m})$ and length $2 b$ (m) is:

$$
\begin{aligned}
T(r, t)= & \frac{Q^{\prime}}{4 \pi \kappa} \int_{r^{2} / 4 \kappa t}^{r^{2} / 4 \kappa\left(t-t_{0}\right)} u^{-1} \exp (-u) \exp \left[-\left(\frac{a}{r}\right)^{2}\right] \\
& \times I_{0}\left(\frac{2 a u}{r}\right) \operatorname{erf}\left(\frac{b}{r} \sqrt{u}\right) \mathrm{d} u, \quad t>t_{0}
\end{aligned}
$$

from a heater coincident with the $z$-axis between $z=-b$ and $z=+b$. Here, $Q^{\prime}$ is the source strength per unit length per unit time $\left(\mathrm{m}^{2}{ }^{\circ} \mathrm{Cs}^{-1}\right)$, equivalent to $q^{\prime} / \rho c_{\mathrm{p}}$, where $q^{\prime}$ is the quantity of heat liberated per unit length of time $\left(\mathrm{J} \mathrm{m}^{-1} \mathrm{~s}^{-1}\right)$. Also, $I_{0}(x)$ represents the modified Bessel function of order zero and $\operatorname{erf}(x)$ represents the error function.

Fig. 2 shows the calculated temperatures at a distance $r=0.006 \mathrm{~m}$ following application of equivalents amounts of energy via instantaneous, Eq. (2), and short-duration, Eq. (8), heat pulses. The short-duration heat pulse causes a significant delay in time at which the maximum temperature change is obtained, but has very little effect on $\Delta T_{\mathrm{M}}$. Because of this minimal effect on $\Delta T_{\mathrm{M}}$, it is possible to use the instantaneous theory with short-duration heat pulses to obtain accurate heat capacities, and hence soil moisture.

For a given $\theta_{\mathrm{v}}$, the sensitivity of $\Delta T_{\mathrm{M}}$ increases as more energy is applied to the probe $q$, but decreases with larger probe spacing and higher bulk densities. The temperature distribution were simulated, using FEMLAB, and the Fig. 3(a) shows the results of the temperature distribution $35 \mathrm{~s}$ after heat-pulse $\left(q=400 \mathrm{~J} \mathrm{~m}^{-1}\right)$ application on a dry soil $(5 \%)$. This simulated results are in agreement with the analitical results showed in Fig. 2. Fig. 3(b) shows a FEMLAB thermal simulation of the sensor where is possible to see that there is no thermal short-circuit between the heater and the temperature probe for the used $6 \mathrm{~mm}$ distance after a $8 \mathrm{~s}$ heat-pulse $\left(q=400 \mathrm{~J} \mathrm{~m}^{-1}\right)$. The simulations also show that the position of the CMOS temperature sensor (reference) in the acrylic block will be in the opposite corner of the heater probe.

\section{Temperature sensor}

A low-cost, small, high-accuracy (better than $0.1 \%$ ), and $0.01{ }^{\circ} \mathrm{C}$ resolution temperature sensor is required to be placed in a stainless steel needle with $0.912 \mathrm{~mm}$ inner diameter and $20 \mathrm{~mm}$ long to obtain a $1 \%$ resolution in soil moisture measurements. A proportional to absolute temperature (PTAT) circuit with bipolar devices fabricated in the CMOS process meet these criteria. Meijer et al. [11] showed that the application of dynamic voltage processing, using dynamic element matching (DEM) and dynamic amplification, will enable to get a very high-performance temperature sensor.

The high-performance CMOS temperature sensor is composed of a dynamic $V_{\text {PTAT }}$ generator with thirty two switching stages. This technique is depicted in Fig. 4 were transistors $\mathrm{M}_{1}-\mathrm{M}_{16}$ represent 16 current mirrors. One of these transistors supplies current to the bipolar transistor $\mathrm{Q}_{1}$ while the other 15 supply current to $\mathrm{Q}_{2}$, so that the current $\left(I_{\mathrm{C} 2}\right)$ passing through $\mathrm{Q}_{2}$ is 15 times the current $\left(I_{\mathrm{C} 1}\right)$ passing through $\mathrm{Q}_{1}$.
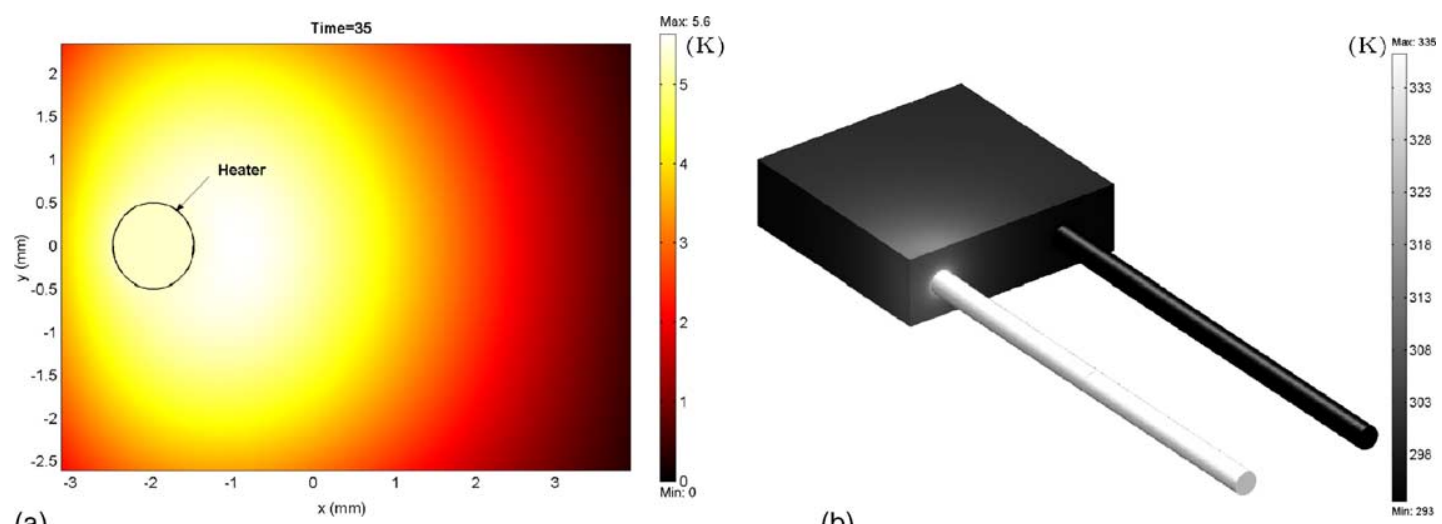

(a)

(b)

Fig. 3. FEMLAB simulation results: (a) soil temperature distribution at $35 \mathrm{~s}$ and (b) thermal simulations of the sensor body. 


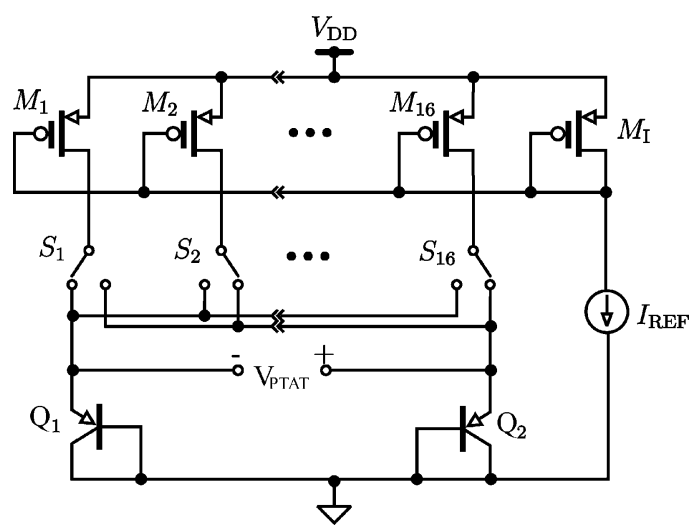

Fig. 4. Generation of $V_{\text {PTAT }}$ using DEM, according to [11].

The collector current versus the base-emitter voltage, $V_{\mathrm{BE}}$ in a transistor is given by:

$V_{\mathrm{BE}}=\frac{\mathrm{k} T}{\mathrm{q}} \ln \left(\frac{I_{\mathrm{C}}}{I_{\mathrm{S}}}\right)$

where $I_{\mathrm{C}}(\mathrm{A})$ is the collector current, and $I_{\mathrm{S}}(\mathrm{A})$ is the saturation current. The difference between the base-emitter voltages $V_{\mathrm{BE} 2}$ and $V_{\mathrm{BE} 1}$ :

$\Delta V_{\mathrm{BE}}=V_{\mathrm{BE} 1}-V_{\mathrm{BE} 2}=\frac{k T}{q} \ln \left(\frac{I_{\mathrm{C} 1}}{I_{\mathrm{C} 2}} \frac{I_{\mathrm{S} 2}}{I_{\mathrm{S} 1}}\right)$

represents the PTAT voltage. Next, using switches, the positions of $\mathrm{M}_{1}-\mathrm{M}_{16}$ are cyclically interchanged. After a complete cycle the averaged results represent a PTAT voltage in which the effect of any mismatch in the characteristic of the transistors $\mathrm{M}_{1}-\mathrm{M}_{16}$ is strongly reduced. In order to eliminate the mismatch in the transistors $\mathrm{Q}_{1}$ and $\mathrm{Q}_{2}$ their relative positions are interchanged as well. So, a complete cycle consists of thirty two sub-cycle states producing an average value of $V_{\text {PTAT }}$ over these states almost equal to $(n k T / q) \ln 15$ (Fig. 5).

The PTAT voltage over a sub-cycle is amplified using a dynamic switched capacitor amplifier with a dc gain of 15 . Fig. 6 shows half of the DEM amplifier. The DEM technique

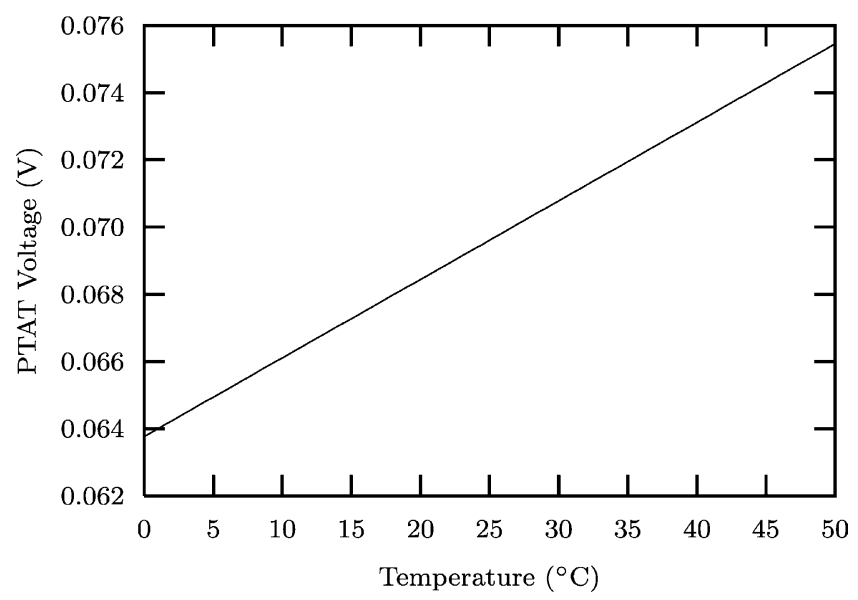

Fig. 5. Simulated PTAT voltage.

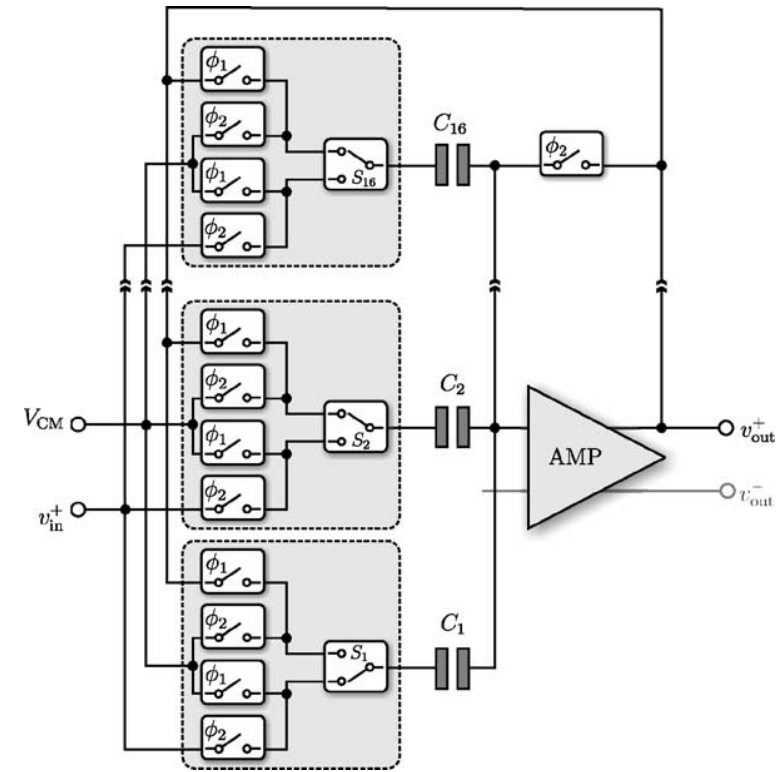

Fig. 6. Half schematic of the DEM amplifier, according to [12].

is realized by sequentially changing the relative positions of the capacitors each clock cycle. In each clock cycle, one of the identical capacitors $\mathrm{C}_{1}-\mathrm{C}_{16}$ is in the feedback position $\left(C_{\mathrm{F}}\right)$ and all the others are in the input position $\left(C_{\mathrm{I}}\right)$. The average value of the amplification factor in a complete cycle is equal to $G=\left(C_{\mathrm{I}} / C_{\mathrm{F}}\right)=15$ where the effect of capacitor mismatching is almost eliminated.

The average of the gain in a complete cycle equals to:

$\bar{G}=\frac{1}{G+1} \sum_{i=1}^{G+1} \frac{\sum_{j=1}^{G+1} C_{j}-C_{i}}{C_{i}}=G+\Delta G$

where $\Delta G$ represents the residual second-order error of the mismatching. So, a complete temperature signal is obtained, after taking an average of the $32 \times 16=512$ sub-cycles (external post-processing).

\section{Results}

Fig. 7 shows a picture of the soil moisture sensor with a microscope photography of the CMOS temperature sensor chip made. The CMOS temperature sensor measures $1108 \mu \mathrm{m} \times 1156 \mu \mathrm{m}$ and was made throw EUROPRACTICE program by IMEC using CMOS technology ALACTEL-MITEC $0.7 \mu \mathrm{m}, \mathrm{n}$-well, C07M-A (2M/1P/PDiffC/HR). In the microscope photography of the CMOS temperature sensor is possible to see the DEM PTAT (A), the DEM amplifier (B), the capacitors of switched-capacitor amplifier (C), and the digital section (D). This test version of the CMOS temperature sensor is square-type and have some test pads. To place this CMOS die in the needle a hole is made and the die is placed in a small PCB and only the needed pads were wire-bonded to obtain the desired signals. 


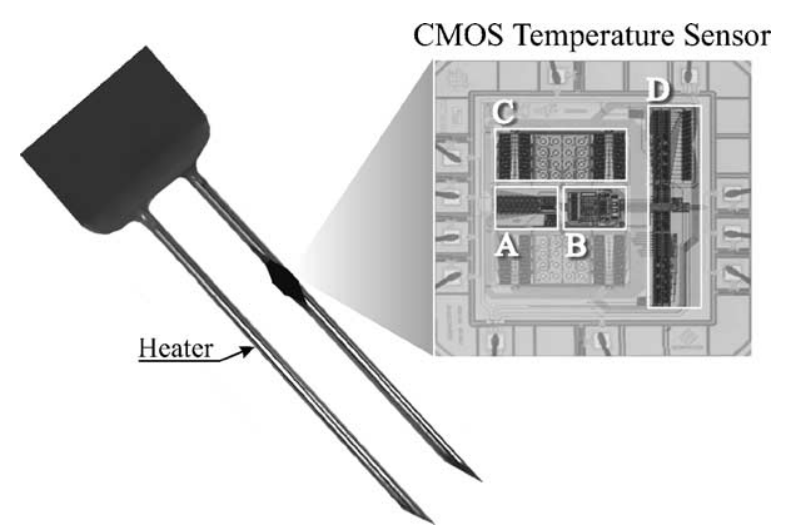

Fig. 7. Temperature sensor layout.

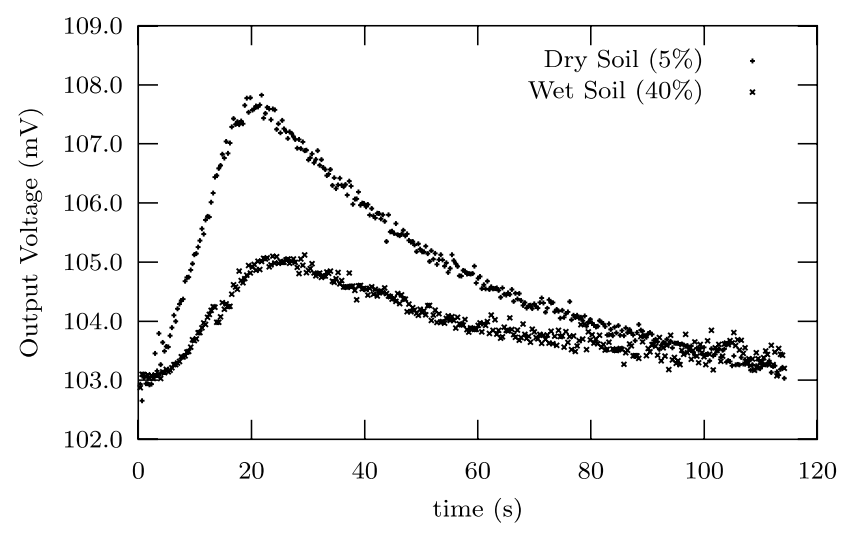

Fig. 8. Results of CMOS temperature sensor placed in the temperature probe for dry $(5 \%)$ and wet $(40 \%)$ soil.

For testing the sensor are used samples of soil oven-dried at $105{ }^{\circ} \mathrm{C}$ and then filed with water to produce $5 \%$ and $40 \%$ of $\theta_{\mathrm{v}}$ with a maximum error of $\pm 1 \%$. Fig. 8 shows the results obtained in the CMOS temperature sensor placed in the temperature probe for wet and dry samples of soil. The values indicate a sensor sensitivity of about $3.5 \mathrm{mV}^{\circ} \mathrm{C}^{-1}$ or $6.825 \mathrm{mV}$ per unit change $\left(\mathrm{m}^{3} \mathrm{~m}^{-3}\right)$ in water content for a heat strength of $400 \mathrm{~J} \mathrm{~m}^{-1}$.

\section{Conclusions}

The modeling and simulation of a soil moisture sensor using the dual-probe heat-pulse method were achieved. A CMOS temperature sensor was fabricated with the use of dynamic PTAT generator and dynamic switched capacitor amplifier in a standard $0.7 \mu \mathrm{m}$ technology. The sensor resolution allows the reduction of the heat-pulse energy to $\left(q=400 \mathrm{~J} \mathrm{~m}^{-1}\right)$ and enable to produce low-cost high-performance soil moisture sensors. The use of a CMOS temperature sensor will bring the possibility to interface to a analog front-end with network solution and external communications (e.g. radio frequency). This micro-system based on dual-probe heat-pulse method has broad utility in soil plant science, because values of soil temperature, heat-capacity, water content, and thermal diffusivity can be determined from a single reading.

It is also shown that the sensitivity of the dual probe is about $1.95^{\circ} \mathrm{C}$ per unit change $\left(\mathrm{m}^{3} \mathrm{~m}^{-3}\right)$ in water content for a heat strength of $q$ of $400 \mathrm{~J} \mathrm{~m}^{-1}$.

More field tests are need to prove the sensor robustness but since the sensor is made from No. 18 steel hypodermic needles $(1.27 \mathrm{~mm}$ o.d., $0.912 \mathrm{~mm}$ i.d., $0.179 \mathrm{~mm}$ wall thickness) they improve rigidity and help to maintain a fixed probe spacing when the sensor was inserted into the soil.

\section{Acknowledgements}

The authors wish to thank the program PRODEP III co-financed by the FSE (European Social Funding) for the partial funding of this work.

\section{References}

[1] G.C. Topp, J.L. Davis, A.P. Annan, Electromagnetic determination of soil water content: measurements in coaxial transmission lines, Water Resour. Res. 16 (3) (1980) 574-582.

[2] G.C. Topp, J.L. Davis, Measurement of soil water content using time-domain reflectometry (tdr): a field evaluation, Soil Sci. Soc. Am. J. 49 (1985) 19-24.

[3] G.S. Campbell, C. Calissendorff, J.H. Williams, Probe for measuring soil specific heat using a heat-pulse method, Soil Sci. Soc. Am. J. 55 (1991) 291-293.

[4] K.L. Bristow, G.S. Campbell, K. Calissendorff, Test of a heat-pulse probe for measuring changes in soil water content, Soil Sci. Soc. Am. J. 57 (1993) 930-934.

[5] J.M. Tarara, J.M. Hamm, Measuring soil water content in the laboratory and field with dual-probe heat-capacity sensors, Agronomy J. 89 (1997) 535-542.

[6] Y. Song, J.H. Hamm, M.B. Kirkham, G.J. Kluitenberg, Measuring soil water content under turfglass using the dual-probe heat-pulse technique, J. Am. Soc. Hort. Sci. 123 (5) (1998) 937941.

[7] A. Valente, J.B. Cunha, C. Couto, Soil moisture sensor with built-in fault-detection capabilities, in: Proceedings of the 24th Annual Conference of IEEE Industrial Electronics Society, Aachen, Germany, 1999, pp. 1310-1314.

[8] A. Valente, C. Couto, J.H. Correia, On-chip integrated silicon bulk-micromachined soil moisture sensor with electronics and bus interface, in: Proceedings of the 2000 IEEE International Symposium on Industrial Electronics, ISIE 2000, Universidad de las Americas, Puebla-Mexico, 2000, pp. 576-579.

[9] D.A. de Vries, Thermal properties of soils, in: W.R. van Wijk (Ed.), Physics of Plant Environment, North-Holland, Amsterdam, 1963.

[10] H. Carslaw, J.C. Jaeger, Conduction of Heat in Solids, Oxford Science Publications, London, 1959.

[11] G.C.M. Meijer, G. Wang, F. Fruett, Temperature sensors and voltage references implemented in cmos technology, IEEE Sens. J. 1 (3) (2001) 225-234.

[12] G. Wang, G.C.M. Meijer, An accurate switched-capacitor amplifier with a rail-to-rail $\mathrm{cm}$ input range, in: Proceedings of the SeSens Workshop, 2000, pp. 703-707. 


\section{Biographies}

A. Valente graduated in electrical engineering at University of Trás-osMontes and Alto Douro (UTAD), Portugal in 1994. He obtained the MSc degree in Industrial Electronics in 1999 at University of Minho, Portugal. He is a PhD student at UTAD, Portugal. Since 1994, he has been a lecturer in the Engineering Department, UTAD, Portugal. He is a researcher at Center of Technological Studies for Environment and Life (CETAV) of the UTAD and he is involved in the research of silicon micro-sensors for agriculture.

R. Morais graduated in electrical engineering at University of Trás-osMontes and Alto Douro (UTAD), Portugal in 1993. He obtained the MSc degree in Industrial Electronics in 1998 at University of Minho, Portugal. $\mathrm{He}$ is a PhD student at UTAD, Portugal. Since 1994, he has been a lecturer in the Engineering Department, UTAD, Portugal. He is a researcher at Center of Technological Studies for Environment and Life (CETAV) of the UTAD and he is involved in the development of instrumentation solutions and mixed-signal sensing interfaces for agricultural applications.
C. Couto graduated in electrical engineering at University of Lourenço Marques, Mozambique in 1972. He obtained the MSc degree in 1979 and $\mathrm{PhD}$ degree in 1981 at University of Manchester Institute of Science and Technology (UMIST), UK, both in power electronics. In 1976, he joined the University of Minho in Portugal, where since 1995, he has been full professor in the Department of Industrial Electronics. His research interests are micro-systems, instrumentation and power electronics.

J.H. Correia graduated in Physical Engineering from University of Coimbra, Portugal in 1990 . He obtained in 1999 a PhD degree at the Laboratory for Electronic Instrumentation, Delft University of Technology, working in the field of micro-systems for optical spectral analysis. Presently, he is an Associate Professor in Department of Industrial Electronics, University of Minho, Portugal. He was the General-Chairman of Eurosensors 2003, Guimaraes, Portugal. His professional interests are in micro-machining and micro-fabrication technology for mixed-mode systems, solid-state integrated sensors, micro-actuators and micro-systems. 